\title{
Influence of timing of surgery on Cauda equina syndrome Outcomes at a tertiary care centre in North-India
}

\author{
Mohammad Ayub Thoker, Sajad Hussain Arif, Abrar Ahad Wani, Nayil Khursheed Malik, \\ Sarabjit Singh Chhibber, Abdul Rashid Bhat, Altaf Umar Ramzan
}

Department of Neurosurgery, SKIMS, Soura

\section{A B S T R A C T}

Background: Acute cauda equina syndrome (CES) is a devastating emergency; the clinicians need to be aware of this entity for early diagnosis and prompt referral to the neurosurgical facility.

Objectives: To study the clinical profile, management and outcome of acute CES in patients referred to a tertiary care hospital.

Study Design: Prospective, Cohort Study

Material and Methods: 29 patientsreferred with a diagnosis of acute CES were studied prospectively. The workup of all the patients included a detailed history, clinical examination, biochemical investigations, and imaging studies.An MRI scan was done in all cases. The details of surgical management and its outcome on follow-up were noted. The outcome was divided into good and bad on the basis of presence or absence of significant motor deficit, and the need for assistance incomplete bladder emptying. Standard methods of statistical analysis wereused, a $p$-value of $<0.05$ was considered statistically significant.

Results: A good outcome was observed in 16 patients (55\%) while the remaining 13 patients $(45 \%)$ hada poor outcome after the surgical intervention. The patients who had unilateral symptoms and those who were operated within 3 days of the onset of symptoms had a better outcome than those operated later $(p<0.05)$. Of all the prognostic factors studied,motor deficit at presentation was observed to be significantlyrelated to poor outcome after surgery.

Conclusion: Acute $\mathrm{CES}$ is a devastating clinical entity with nearly half of the patients havinga poor outcome.In patients presenting with clinical involvement of a lesser magnitude, a better outcome is observedwith early surgery

Keywords: cauda equina, motor deficit, spine, spinal surgery, surgical outcome

JMS: 2020; 23(1):16-21 DOI: https://doi.org/10.33883/jms.v23i1.501

\section{INTRODUCTION}

Cauda equina is a bundle of nerves consisting of sensory and motor nerve roots emerging from conus medullaris within the spinal canal. Any compression to the cauda equina leads to a syndrome known as cauda equina syndrome (CES). This syndrome, first time described in 1934 by Mixter and Barr,1 is characterized by severe low backache, radiculopathy (unilateral/bilateral), peri-anal anesthesia, bowel and bladder involvement, motor and sensory deficit, erectile dysfunction (males), and decreased ankle/knee reflexes.1-3 Red flag signs onpresentationof this syndrome

\begin{tabular}{|l|l|}
\hline \multicolumn{2}{c}{ Access this article online } \\
\hline
\end{tabular}

include:i) Severe low backache (recent onset) with or without radiculopathy, ii) saddle anesthesia,iii) Bowel/bladder disturbances, iv) Peri-anal anesthesia/ hypoesthesia, v) Motor and/or sensory deficit, and vi) decreased tendon reflexes (ankle jerk in particular). Patients are sub-classified into complete or incomplete CES

Correspondence:

Dr. Abrar Ahad Wani, MCh

Additional Professor

Department of Neurosurgery, SKIMS, Soura

E-mail: abrarwani@rediffmail.com

How to cite this article: Thoker M, Arif SH, Wani AA, Malik NK, Chhibber SS, Bhat AR, Ramzan A U. Influence of timing of surgery on Cauda equina syndrome: Outcomes at a tertiary care centre in North-India. JMS 2020;23(1):16-21

Received: 2019-12-16 Accepted: 2020-03-13 
Thoker MA, et al; Influence of timing of surgery on Cauda equina syndrome Outcomes at a tertiary care centre

depending on the severity of neurogenic lower urinary tract dysfunctionat the time of presentation. Patients with incomplete CES may have altered urinary or anal sensation, genital sensory disturbance in S3-S5 region, incontinence, loss of desire to void, poor urinary stream, and the need to strain in order to micturate. Complete CESis characterized by painless urinary retention and overflow incontinence requiring indwelling catheter placement due to complete bladder motor paralysis.

The etiology of CES include other compressive pathologiesin cauda equine region like trauma, tumor and degenerative disc disease. ${ }^{2-5}$ Disc prolapse is the most common cause of CES though the pathophysiology of CES is not quite clear. CESis a rare disease affecting 2-3\% of lumbar disc patients with an incidence of 1/100,000.6 In developing countries the incidence is more because of lack of medical facilities and late presentation of patients. Prognostic factors of CES outcome are not very clear. While some authors recommend that early diagnosis and early decompression is the best way to minimize postoperative neurodeficit, many authors, on the contrary, suggest that early decompression is not a favorable predictor for post-op recovery. ${ }^{8-11}$ Therefore, the present study was carried out to study the aetiology, level of compression, clinical presentation, symptom onset to intervention time, and outcome of acute CES in patients presenting to our centre in the last two years.

\section{MATERIALS AND METHODS}

Twenty-nine patients presenting to our centre with a diagnosis of acute cauda equine syndrome were studied prospectively. Only those patients who followed for at least 6 months were included in the study. Details of the history, investigations, and treatment received before presenting to our centre were noted on a proforma. The work up of all the patients included a detailed clinical examination and an MRI scan. As per departmental protocol, patients were operated in the earliest operating slot available. In the follow-up, patients were reassessed 3 monthly, and details of the outcome were noted. The outcome was divided into good and poor, based on the presence or absence of significant motor deficit (MRC grade of less than 4) and need for some assistance incomplete bladder emptying.

\section{STATISTICALANALYSIS:}

Data analysis was done on an MS Windows-based PC computer using Epi Info ${ }^{\mathrm{TM}}$, version 7.1.5.2, from Centers for Disease Control and Prevention (CDC) for statistical analysis. Data were expressed as Mean $\pm \mathrm{SD}$ or percentage, whichever was appropriate for the patient's characteristic description. Group differences were compared using the Pearson chi-square or Fisher's exact test for categorical variables, and the Student t-test or the Mann-Whitney U test for continuous variables. The relation of each parameter was sought in each patient with the postoperative outcome for the assessment of prognostic factors. To measure the strength of the relationship betweenvarious prognostic factors and postoperative outcome, the Pearson correlation coefficient or Spearman rank correlation was used, as appropriate for the variable distribution. All values were calculated as 2-tailed and a $\mathrm{P}$ value of 0.05 or less was considered statistically significant.

\section{RESULTS}

Of 29 patients presenting with symptoms of acute CES who were enrolled for the study, 17 (59\%) patients were males and $12(41 \%)$ were females. All the patients were adults and had degenerative disc disease or acute disc prolapse. In $85 \%$ of the patients, disc disease was at L4-L5 or L5-S1 levels whereas in the remaining $15 \%$ it was between L2-L4 levels. The cause of CES in all the study patients was a disc prolapse (Fig. 1) and/or canal stenosis (Fig. 2). There was no history of significant trauma in any of the patients whereas three patients had a history of lifting heavyweight prior to the onset of symptoms. None of the patients could be diagnosed and operated in less than 48 hours due to late referral to our hospital and logistics involved in getting MRI scans. Nonetheless, surgery was done as soon as possible and on the basis of interval time between the onset of symptoms and date of surgery, the patients were divided into two treatment groups. One, where surgery was done within 48-72 hours $(n=14)$ and the other group who were operated after 72 hours. The follow up was between 6-20 months (mean follow-up, 9.8 months). For post-operative assessment, patients were arbitrarily divided into two groups on the basis of outcome, i) good outcome, and ii) poor outcome. Poor outcome was defined on the basis of significant motor deficit (MRC grade of less than 4) and the need for some assistance in bladder emptying(Table 1).

A poor outcome was seen in 13 out of 29 subjects (45\%) while the remaining 16 subjects (55\%) had a good outcome. 
Thoker MA, et al; Influence of timing of surgery on Cauda equina syndrome Outcomes at a tertiary care centre

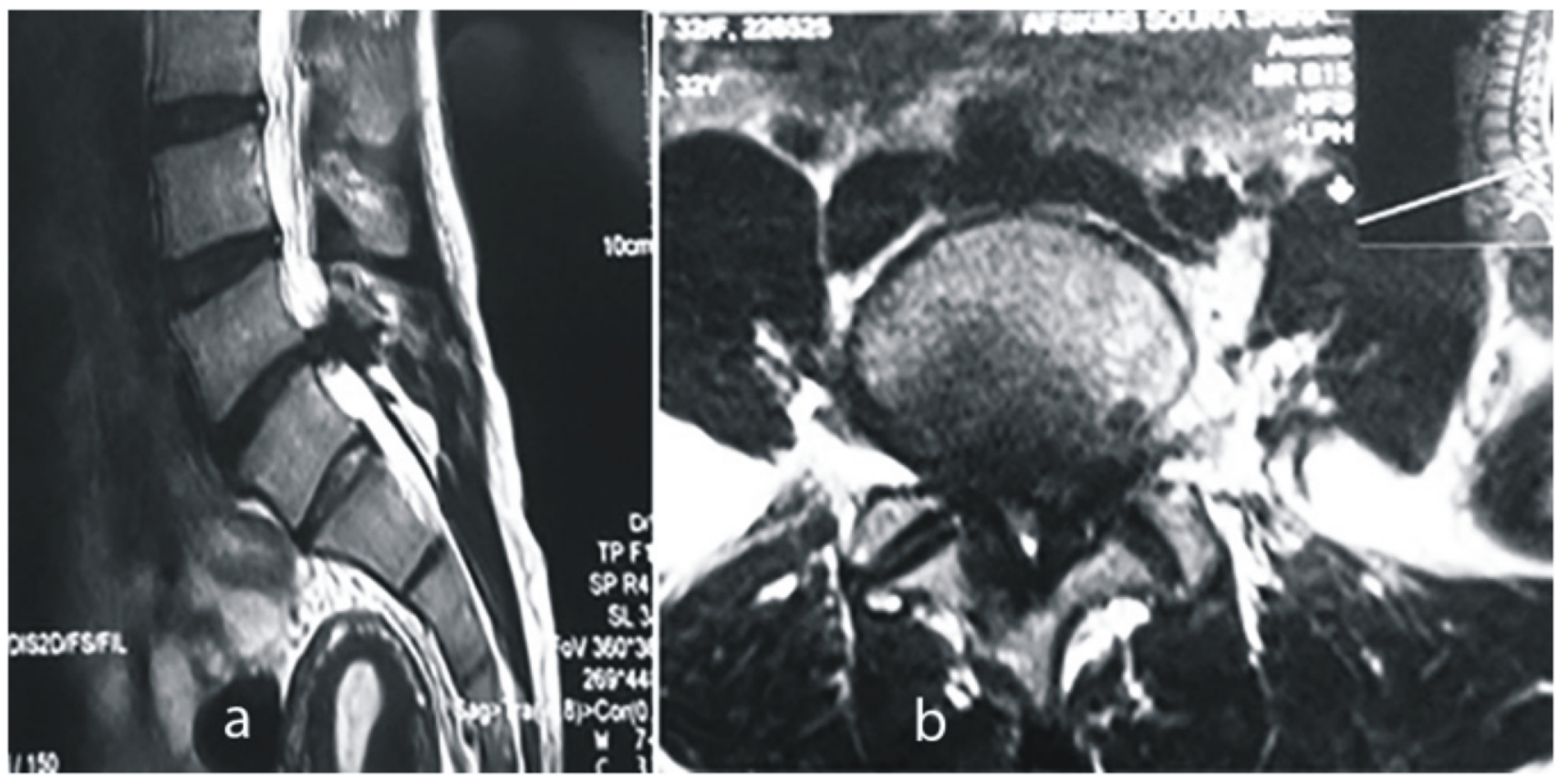

Fig 1.Sagittal (a) and axial (b) MRI axial showingL4-5disc prolapse withsevere compression of the thecal sac and exit roots
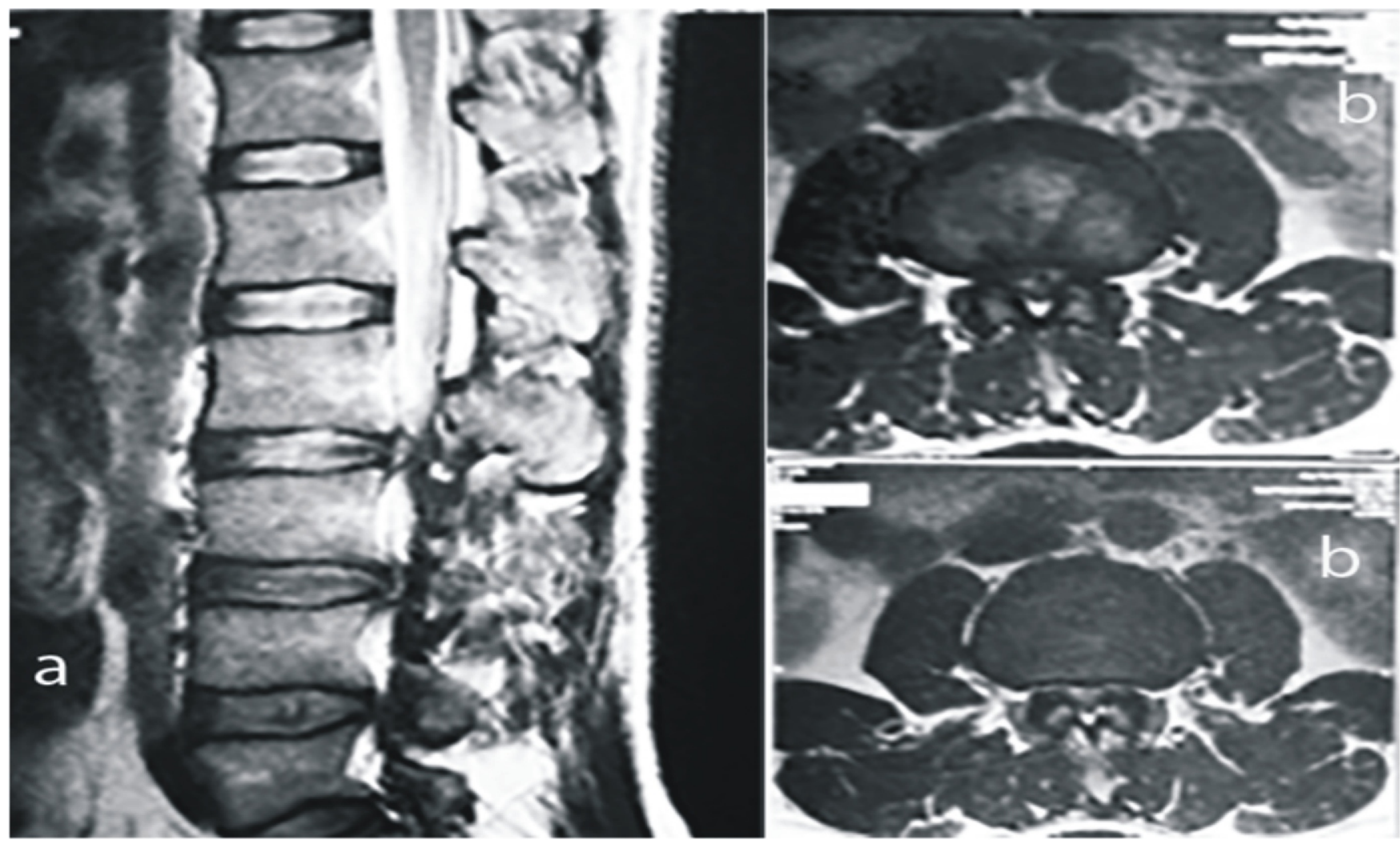

Fig 2.Sagittal (a) and axial (b) MRI axial showing lumbar canal stenosis with severe compression of the thecal sac and exit roots 
Thoker MA, et al; Influence of timing of surgery on Cauda equina syndrome Outcomes at a tertiary care centre

The pattern of neurological recovery observed in our patients was motor power followed by bowel and bladder function, followed by sensory function. In the postop period, the time of recovery ranged from 3 to 12 months. Out of 16 patients who had a good outcome $12(85.7 \%)$ were operated within 72 hours from the onset of the disease and 4 (26.7\%)were operated after three days from the onset of disease. None of the patients was operated in less than 24 hours of the onset of symptoms. 11 out of 13 patients ( $86 \%$ ) who had poor outcomes were operated after 3 days from the onset of disease and $2(14.3 \%)$ patients were operated within three days from the onset of disease. Our observations clearly favour, the earlier the decompression better is the outcome (Table 1).

Table 1. Comparison of various prognostic factors: good outcome vs poor outcome

\begin{tabular}{|c|c|c|c|}
\hline \multirow[b]{2}{*}{ Prognostic factor } & \multicolumn{2}{|c|}{ Outcome } & \multirow{2}{*}{$\begin{array}{c}\mathbf{P} \\
\text { Value }\end{array}$} \\
\hline & $\begin{array}{c}\text { Good } \\
(n=16)\end{array}$ & $\begin{array}{c}\text { Poor } \\
(n=13)\end{array}$ & \\
\hline Female gender & $7(43.8 \%)$ & $5(38.5 \%)$ & $>0.7$ \\
\hline Age $($ Mean $\pm S D)$, years & $48.3 \pm 2.12$ & $\begin{array}{r}39.56 \\
\pm 3.67 \\
\end{array}$ & $<0.05$ \\
\hline $\begin{array}{l}\text { Heavy weight lifting as } \\
\text { precipitating factor }(n=3)\end{array}$ & $2(12.5 \%)$ & $1(7.6 \%)$ & $>0.8$ \\
\hline $\begin{array}{l}\text { Bilateral symptoms in } \\
\text { preoperative period }(n=17)\end{array}$ & $5(31.3 \%)$ & $\begin{array}{c}12 \\
(92.3 \%) \\
\end{array}$ & $<0.001$ \\
\hline $\begin{array}{l}\text { Preoperative bowel \&/or } \\
\text { bladder dysfunction }(n=25)\end{array}$ & $14(87.5 \%)$ & $\begin{array}{c}11 \\
(84.6 \%) \\
\end{array}$ & $>0.8$ \\
\hline $\begin{array}{l}\text { Preoperative Perianal } \\
\text { hypoesthesia }(n=29)\end{array}$ & $16(100 \%)$ & $\begin{array}{c}13(100 \\
\%)\end{array}$ & - \\
\hline $\begin{array}{l}\text { Preoperative Motor deficit } \\
(\mathrm{n}=17)\end{array}$ & $4(25 \%)$ & $\begin{array}{c}13(100 \\
\%)\end{array}$ & $<0.001$ \\
\hline $\begin{array}{l}\text { Onset to surgery interval of } \\
>72 \text { hours }(n=15)\end{array}$ & $4(25.0 \%)$ & $\begin{array}{c}11 \\
(84.6 \%)\end{array}$ & $<0.002$ \\
\hline
\end{tabular}

\section{DISCUSSION}

We prospectively enrolled all the patients who presented with symptoms of (CES); the following observations were made. All the patients were adults, had degenerative disc disease or acute disc prolapse as the etiology of CES. No patient had a significant history of trauma and three patients had a history of lifting heavyweight prior to the onset of symptoms. None of the patients could be diagnosed and operated in less than 48 hours due to late referral to our hospital and logistics involved in getting MRI scans done in the developing world. Nonetheless, the surgery was done as soon as possible. The follow up was from 6 months to 20 months (mean, 9.8 months). A good outcome was seen in 16 out of 29 patients. The pattern of neurological recovery in our patients as; motor power followed by bowel and bladder followed by sensory. Period of recovery postoperatively ranged from 3 to 12 months.

Cauda equina syndrome, first described by Mixter and Barr in 1934 isa rare condition affecting 2-3\% patients of lumbar disc protrusion with an incidence of 1 in 100,000/year. ${ }^{12-15}$ Disc prolapse is the most common cause of CES. 16 There is a general consensus that CES is a surgical emergency. Surgery should be done by experienced surgeons because excessive manipulation and handling of dura and roots can lead to permanent neuro deficits. Some authors like Kostuik et al and $\mathrm{O}$ Laoire et al says that there is no correlation between duration of symptoms intervention in cauda equina with the postoperative outcome. ${ }^{8}$ On the other hand,Ahn et al and Kohleas noted that shorter the time duration between symptoms intervention in cauda equina, better is the postoperative outcome.17-20Most of the authorities advocate early surgical intervention to halt the progression of symptoms. ${ }^{8}$

Out of 16 patients who had a good outcome 12 (85.71\%) were operated within 72 hours from the onset of the disease and $4(26.66 \%)$ were operated after three days from the onset of disease. 11 (85.71\%). Out of 13 patients who had poor outcomes were operated after 3 days from the onset of disease and 2 (14.28\%) patients were operated within three days from the onset of disease. Better neurological recovery is seen in patients with earlier surgical intervention. Our observations were supported by; Shepard et al, Kostuick et al. and Nielson et al earlier the decompression better is the outcome. ${ }^{4,21}$ For better neurological recovery huge data is available which supports the early surgical intervention. ${ }^{5,9,11,13}$ Early surgical decompression will halt the progression of symptoms from partial to complete neurological deficit. In our study, $45.6 \%$ of patients did not show any improvement in perianal sensation after surgical decompression. McCarthy et al. in his study reported the least improvement in perianal sensation after surgery and Dinning et al in his study showed the least sensory improvement following surgery. ${ }^{22,23}$ Surgery should be done by experienced surgeons because excessive manipulation 
Thoker MA, et al; Influence of timing of surgery on Cauda equina syndrome Outcomes at a tertiary care centre

and handling of dura and roots can lead to permanent neuro deficits. $^{24,25}$

We did not find any significant correlation between the level of compression and neurological outcome after surgery. In our study backache with radiculopathy was a presenting symptom in all cases of Cauda equina. Bilateral symptoms were seen in 17 patients of which only 5 (29.41\%) had a good outcome and $12(70.58 \%)$ had a poor outcome. $(p<0.05)$. Our observations are consistent with the O'Laoire et al. and others, that bilateral radiculopathy isa poor predictor of outcome in Cauda equina. $3,9,10$

\section{CONCLUSION}

CES is a devastating emergency with a very low incidence and the commonest etiology is degenerative disc disease. We observed poor outcomes with the presence of bilateral symptoms at presentation, significant motor deficit and delay in surgery. The clinicians need to be made aware of the entity so that the investigations and referrals to the neurosurgical facility are made at the earliest.

\section{Declaration}

Ethical Approval: Taken

Consent: Taken

Competing interest: Nil

Funding: Nil

\section{REFERENCES}

1. Oppenheim H, Krause F. Uber einklemmungbzw: strangulation der cauda equina. Dtsch Med Wochenschr 1909; 35:697700

2. Benzel EC, Hadden TA, Coleman JC Civilian gunshot wound to the spinal cord and cauda equina. Neurosurgery 1987;20:281285

3. Cybulski GR, Stone JL, Kano R Outcome of laminectomy of civilian gunshot injuries of the terminal spinal cord and cauda equina: a review of 88 cases. Neurosurgery 1989;24:392397

4. Kostuik JP, Harrington I, Alexander D CES and lumbar disc herniation. J Bone Joint Surg [Am] 1986; 68:386391

5. Tay EK, Chacha PB Midline prolapse of a lumbar intervertebral disc with compression of the cauda equina. J Bone Joint Surg [Br] 1979; 61:4346
6. Fraser S, Roberts L, Murphy E. CES: a literature review of its definition and clinical presentation. Arch Phys Med Rehabil 2009;90 (11):19641968

7. Tandon PN, Sankaran B CES due to lumbar disc prolapse. Indian J Orthop (1967); 1:112119

8. Kostuik JP, Harrington I, Alexander D et al CES and lumbar disc herniation. J Bone Joint Surg [Am] 1986; 68:386391

9. O'Laoire SA, Croakard HA, Thomas DG Prognosis for sphincter re-covery after operation for cauda equina compression owing to lumbar disc pro-lapse. BMJ 1981; 282:18521854

10. Delamater RB, Sherman JE, Carr JB CES. Neurological recovery following immedi-ate, early or late decompression. Spine 1991; 16:10221029

11. Jennett WB A study of 25 cases of compression of the cauda equina by prolapsed intervertebral discs. J NeurolNeurosurg Psychiatry 1956; 19:109

12. Luschka H. Die Halbgelenke des menschlichenKörpers. EineMonographie. Berlin, Germany: Reimer; 1858

13. Oppenheim H, Krause F. Übereinklemmungbzw: strangulation der cauda equina. Dtsch Med Wochenschr 1909; 35:697700

14. Tait MJ, Chelvarajah R, Garvan N, Bavetta S. Spontaneous hemorrhage of a spinal ependymoma: a rare cause of acute CES. Spine 2004;29: E502-5.

15. Fraser S, Roberts L, Murphy E. CES: a literature review of its definition and clinical presentation. Arch Phys Med Rehabil 2009;90 (11):19641968

16. Garfin SR, Rydevik BL, Brown RA. Compressive neuropathy of spinal nerve roots.A mechanical or biological problem? Spine 1991;16(2):162166

17. Shapiro S. CES secondary to lumbar disc herniation.Neurosurgery. 1993;32 (5):743-746.

24. Alastair Gibson JN, Waddell Gordon Surgical interventions for lumbar disc prolapse; updated cochrane review. Spine 2007; 32:17351747

25. Gleave JRW, Macfarlane R. CES: what is the relationship between timing of surgery and outcome? Br J Neurosurg 2002;16(4):325328

18. Ahn UM, Ahn NU, Buchowski JM, et al. Cauda 
Thoker MA, et al; Influence of timing of surgery on Cauda equina syndrome Outcomes at a tertiary care centre

Equina syndrome secondary to lumbar disc herniation: a meta-analysis of surgical outcomes. Spine2000; 25:348-352

19. Shapiro S CES secondary to disc herniation. Neurosurgery 1993; 32:743747

20. Kohles SS, Kohles DA, Karp AP, Erlich VM, Polissar NL. Time-dependent surgical outcomes following cauda equina syndrome diagnosis: comments on a meta-analysis. Spine 2004;29 (11):12811287

21. Nielson B, deSully M, Schmidt K, Hansen RJ A urodynamic study of CES due to lum-bar disc herniation. UrolInt 1980; 35:167 170
22. McCarthy MJH, Aylott CEW, Grevitt MP et al CES: factors affecting long-term functional and sphincteric outcome. Spine 2007;32 (2):207216

23. Dinning TAR, Schaeffer HR Discogenic compression of the Cauda Equina: a surgical emergency. Aust NZ J Surg 1993; 63:927934

24. Alastair Gibson JN, Waddell Gordon Surgical interventions for lumbar disc prolapse; updated cochrane review. Spine 2007; 32:17351747

25. Gleave JRW, Macfarlane R. CES: what is the relationship between timing of surgery and outcome? Br J Neurosurg 2002;16(4):325328 